\title{
Effect of gamma irradiation on indigenous fresh produce
}

\section{Lilesh Pustode, Deepak Bornare and Hanuman Bobade}

Received : $10.04 .2018 ;$ Accepted : 13.04 .2018

See end of the Paper for authors' affiliation

Correspondence to :

Lilesh Pustode Department of Agricultural Engineering, Maharashtra Institute of Technology, Aurangabad (M.S.) India
- Abstract : Indigenous fresh produce has enormous potential to contribute in food and nutritional security. It also contributes with essential micronutrients in the daily diet. The indigenous fresh produce has a short shelf life and they get affected during storage and transportation due to microbial spoilage. Traditionally, this problem is addressed by providing a controlled atmosphere to the fresh produce, which is quite costly and effective only for short duration. Irradiation treatment could also be applied to mitigate this problem. Irradiation helps to eliminate various microorganisms, delay ripening, sprout inhibition and extension of shelf life of indigenous fresh produce. Cobalt-60 is the radioisotope used as a source of irradiation. Gamma radiation in a controlled amount about 1-3 kGy penetrates the pre-packed food commodities to extend the shelf life by 15-20 days without affecting nutritional quality and safety of food. This process is effective in reducing pathogens such as E. Coli, Salmonella Paratyphi A. Gamma radiations do not make food radioactive, change in appearance, texture or color and comprised nutritional quality. Also application of spent nuclear fuel in such processing unriddles the problems of nuclear waste disposal and management in some extent. Thus, such technology can augment processing of fresh produce and control post harvest losses in developing countries like India.

Key words : Cobalt-60, Gamma Radiations, Indigenous food, Irradiation, Post harvest losses, Shelf life

- How to cite this paper : Pustode, Lilesh, Bornare, Deepak and Bobade, Hanuman (2018). Effect of gamma irradiation on indigenous fresh produce. Internat. J. Agric. Engg., 11(Sp. Issue) : 137-141, DOI: 10.15740/HAS/IJAE/11.Sp. Issue/137-141. 